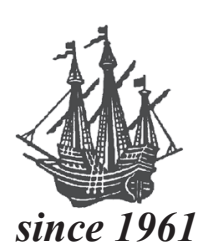

BALTICA Volume 34 Number 2 December 2021: 157-173

https://doi.org/10.5200/baltica.2021.2.3

\title{
Statistical behaviours of earthquake occurrences in the Central Anatolian Region of Turkey: region-time-magnitude analyses
}

\section{Serkan Öztürk}

Öztürk, S. 2021. Statistical behaviours of earthquake occurrences in the Central Anatolian Region of Turkey: region-timemagnitude analyses. Baltica, 34 (2), 157-173. Vilnius. ISSN 1648-858X.

Manuscript submitted 19 April 2021 / Accepted 21 October 2021 / Available online 15 November 2021

(C) Baltica 2021

\begin{abstract}
The main objective of this work is to make detailed region-time-magnitude analyses by describing the statistical behaviours of earthquakes in the Central Anatolian Region of Turkey. In this scope, several seismic and tectonic parameters such as $M c o m p, b$-value, $D c$-value, $Z$-value, recurrence times and annual probabilities were evaluated. For the analyses, a homogeneous catalogue including 10,146 earthquakes with $1.0 \leq M_{d} \leq 5.7$ between 30 July 1975 and 29 December 2018 was used and spatio-temporal changes of earthquake behaviours were mapped for the beginning of 2019. Earthquake magnitudes varied from 1.9 to 3.0 on average, and hence Mcomp was considered to be 2.6. The $b$-value was calculated as $1.26 \pm 0.07$, and this relatively large value indicates that small-magnitude events are dominant. The $D c$-value was computed as $1.31 \pm 0.03$. This small value means that distances between epicentres approach the diameter of the cluster, and seismic activity is more clustered at smaller scales or in larger regions. The spatio-temporal analyses of recurrence times suggest that the Central Anatolian Region has an intermediate/long-term earthquake hazard in comparison to occurrences of strong earthquakes in the short term. Several anomaly regions of a small $b$-value and a large $Z$-value were found in and around the Tuzgölü Fault Zone, Central Anatolian Fault Zone, Salanda fault and Niğde fault at the beginning of 2019. Thus, a combination of the regions with a lower $b$-value, a higher Z-value and also moderate recurrence times may give significant clues for the future possible earthquakes, and detected regions may be thought to be the most likely areas for strong/large events in the Central Anatolian Region.
\end{abstract}

Keywords: spatio-temporal analysis; Mcomp; b-value; Dc-value; Z-value

Serkan Öztürk (serkanozturk@gumushane.edu.tr), Gümüşhane University, Department of Geophysics, TR-29100, Gümüşhane, Turkey

\section{INTRODUCTION}

Statistical evaluation of region-time-magnitude distributions of earthquake occurrences is a significant step to make quantitative the seismic hazard studies, and these types of numerous analyses have been carried out by different researchers for different parts of the earth. Many authors have revealed some important results in recent years by considering the basic and the most frequently used seismological parameters such as $(i)$ regional, temporal and magnitude distribution of seismic activity, $(i i)$ magnitude completeness, Mcomp, which describes the minimum magnitude of complete reporting, (iii) $b$-value, which is stated as the power-law distribution of seismicity, (iv) $D c$-value, which defines the self-similarity of a geometrical object, $(v)$ standard normal deviate $Z$-value, which is one of the most frequently used tool in terms of the observation of seismicity rate changes, and $(v i)$ annual probabilities and recurrence times for specific magnitude values (e.g., Frohlich, Davis 1993; Wiemer, Wyss 2000; Öncel, Wilson 2002; Polat et al. 2008; Roy et al. 2011; Öztürk 2013; Ali 2016; Rodriguez-Perez, Zuniga 2018; Radziminovich et al. 2019; Öztürk, Şahin 2019; Zuniga et al. 2020). 
Detailed statistical studies indicate that behaviours of earthquake occurrences show fractal and chaotic properties, and these characteristics are sophisticated statistical tools in defining the earthquake distributions and their randomness (Goltz 1998). The fractal dimension, $D c$-value, describes the heterogeneity of seismicity in an active fault system, and some geological, mechanical or structural variations in heterogeneity can be explained by using fractal dimension. For this reason, the fractal dimension of earthquakes has widely been used as an effective tool to investigate the seismic hazard for different regions of the earth in recent years (e.g., Matcharashvili et al. 2000; Öncel, Wilson 2004; Chen et al. 2006; Pailoplee, Choowong 2014; Öztürk 2018; Telesca, Chen 2019). These studies suggest that evaluation of fractal behaviours of earthquake distribution may be correlated with the seismogenic stress situations during seismic activity and may be related to the next earthquake hazard (Gnyp 2007). Another scaling law of earthquake distributions can be given as the Gutenberg-Richter (G-R) frequency-magnitude relation (Gutenberg, Richter 1944). Thus, detailed studies show that the $b$-value does not only reflect the relative proportion of small and great events, but it can also be related to the properties of the seismogenic elements and spatial-temporal-depth changes of stress (Utsu 1971). For this reason, the $b$-value is one of the best known statistical parameters of earthquake occurrences, and a large number of studies on the G-R relation can be found for different parts of the earth (e.g., Enescu, Ito 2002; Polat et al. 2008; Öztürk 2011, 2015; Singh 2016; Chiba 2019). In addition to the fractal dimension and the G-R relation, spatio-temporal changes in the earthquake activity rate have also been evaluated as an earthquake precursor. The precursory seismic quiescence is described as an important decrease in the average activity rate compared to the background rate (Wyss, Martirosyan 1998). There are many studies on the analysis of precursory quiescence before the main shock, and these studies reveal that significant decrease in the activity can be observed in and around focal areas in a few years before the main shock (e.g., Wyss, Burford 1987; Console et al. 2000; Wu, Chiao 2006; Katsumata 2011; Öztürk 2017; Gentili et al. 2019). Finally, these studies emphasize that the use of these types of techniques as a method of earthquake hazard evaluation may be important and can supply sufficient knowledge of the regional seismo-tectonic evolution (Bowman, King 2001a, b).

Turkey is one of the most significant earthquake regions of the earth, and hence many statistical studies on the behaviours of earthquake occurrences have been realized to evaluate the seismic potential for different parts of Turkey (e.g., Öncel, Wilson 2004; Polat et al. 2008; Özmen 2015; Öztürk 2018). It is well known that the Central Anatolian Region (CAR) of Turkey has no significant earthquake potential with regard to occurrences of strong/large earthquakes in the short term. However, a few strong earthquakes occurred in the past and recent years, such as BalaAnkara (M5.3) on 4 July 1978, Bala-Ankara (M5.0) on 21 April 1983, Bala-Ankara (M5.7) on 20 December 2007, Bala-Ankara (M5.5) on 27 December 2007, Hacıdurakl1-Kırşehir (M5.1) on 10 January 2016, and Bor-Niğde (M5.1) on 20 September 2020. In addition, these types of evaluations related to possible correlation between seismic and tectonic parameters are relatively rare for the CAR. Therefore, the main purpose of this paper is to provide up-to-date and reliable information on earthquake hazard assessments in the CAR at the beginning of 2019.

The spatio-temporal properties of the seismicity pattern are significant to better understand the seismic hazard. For this purpose, a detailed statistical evaluation of two basic size-scaling parameters, the $b$ value of the G-R relation and the $D c$-value of fractal dimension, was achieved. In this way, it was aimed to ensure some additional information regarding the next seismic hazard in this part of Turkey. Also, some statistical assessments of magnitude completeness (Mcomp), seismic quiescence ( $Z$-value), annual probability and recurrence time of the earthquakes for different magnitude levels were made in order to put forth the current and future earthquake potential. In this scope, all calculations were made by applying the ZMAP software package (Wiemer 2001), and a new release of ZMAP consists of many tools including statistical analyses. The results obtained in this study will have importance not only for the regiontime-magnitude characteristics of earthquake occurrences but will also help understand the earthquake generation in the CAR. As a result, these tools can provide valuable evidences to earthquake hazard researches and lead to achieve evaluation for forecasting future earthquake occurrences in the real time for this region.

\section{EARTHQUAKE DATABASE AND MAIN TECTONICS IN THE CENTRAL ANATOLIAN REGION}

The earthquake database analyzed in this study was taken from Öztürk (2009) for the time interval between 1970 and 2006. Öztürk (2009) produced several empirical equations to obtain a homogeneous and complete earthquake catalogue. Thus, he prepared an instrumental earthquake dataset for duration magnitude $M_{d}$ including 73,530 events between 1970 and 2006 (the relations of different magnitude scales can be found in detail in Bayrak et al. 2009). Also, the catalogues of Bogazici University's Kandilli Observ- 
atory and Research Institute (KOERI) and of Disaster and Emergency Management Authority (AFAD) were used for the time period from 2006 to 2019 . These stations have high-gain seismometers and the errors of hypocenter distributions are approximately 2 or $3 \mathrm{~km}$ depending on the distribution of stations. Each station, particularly after 2000 , mostly provides $M_{d}$ for all events. They however provide local magnitudes, $M_{L}$, for the earthquakes for which $M_{d}$ had not been calculated in recent years. In the situations where $M_{d}$ was not calculated in KOERI and AFAD catalogues between 2006 and 2019, unknown $M_{d}$ were calculated from $M_{d}-M_{L}$ equations suggested by Öztürk (2009). The catalogue includes a total of 176,199 events for Turkey from 2006 to 2019. Finally, a catalogue consisting of 249,729 earthquakes in and around Turkey from 1970 to 2019 was provided.

KOERI and AFAD provide real time data, particularly after 2000 , by using modern on-line and dial-up seismic terminals in Turkey, and $M_{d}$ of the earthquakes (occasionally $M_{L}$ or different magnitude scales) is calculated by them. The signals from the stations are sent by phone lines or by radio waves to the seismological centres. There is a large number of terminals of KOERI and AFAD in all parts of Turkey, and they estimate the location and magnitude of events as accurately and fast as possible. Regarding the precision of the earthquake database used in this study, it can be stated that errors in epicentres are within $0-5 \mathrm{~km}$ and errors in magnitudes are within 0.2 for the earthquakes since 1970s. However, the corresponding errors for the events prior to the $1970 \mathrm{~s}$ are $0-30 \mathrm{~km}$ in epicentres and 0.5 in magnitudes (see Bogazici University home page for details, http://www.koeri.boun.edu.tr). Therefore, the epicentres of events were not relocated, and the magnitudes and locations of earthquakes supplied by KOERI and AFAD were used.

The boundaries of the study area were drawn by considering Öztürk (2012). Turkey was divided into 55 different source zones as in Öztürk (2012) (Fig. 1a) by using several criteria such as previous seismic hazard modelling studies, focal mechanisms of earthquakes, tectonic structures and epicentre distribution of earthquakes (detailed seismotectonic zonation studies can be found in Erdik et al. (1999), Bayrak et al. (2009), and Öztürk (2012)). Since Öztürk (2012) achieved a detailed seismic zonation study for Turkey, three parts including the CAR were selected as the study region. Thus, the CAR (regions 53, 54 and 55 in Öztürk 2012) covered by the coordinates $35^{\circ} \mathrm{N}$ and $41^{\circ} \mathrm{N}$ in latitude and $31^{\circ} \mathrm{E}$ and $39^{\circ} \mathrm{E}$ in longitude was considered. The simplified tectonics of the study area were modified from different researchers such as Şaroğlu et al. (1992), Bozkurt (2001), Ulusay et al. (2004) and are plotted in Fig. 1b. After choosing the CAR, the earthquake database was prepared. As the first step, the earthquakes between 1970 and 2019 were selected from the database. Magnitude type was selected as $M_{d}$ in this work, and the catalogue was completed for all magnitude levels and time intervals. Then, the earthquake database was prepared for the time interval between 30 July 1975 and 29 December 2018, and this time length is about 43.42 years. Finally, 10,146 events with magnitudes greater than or equal to 1.0 with depth $<70 \mathrm{~km}$ between 1975 and 2019 were totally obtained. The epicentre distributions of all $M_{d} \geq 1.0$ earthquakes (with different symbols for different magnitude levels) and strong/large earthquakes $\left(M_{d} \geq 5.0\right)$ in the study area are shown in Fig. 1c.

Turkey is one of the most seismically and tectonically active regions on the earth, and the movements in and around Turkey result from relative activities between different plates, such as African, Arabian, Aegean, Anatolian, Black Sea and Eurasian plates. Turkey is located in the Mediterranean part of AlpineHimalayan orogenic system, and the most significant tectonic structures can be given as the Aegean Arc, West Anatolian Graben Systems (WAGS), North Anatolian Fault Zone (NAFZ), East Anatolian Fault Zone (EAFZ), Bitlis-Zagros Thrust Zone (BZTZ), North East Anatolian Fault Zone (NEAFZ), Dead Sea Fault Zone (DSFZ), and Caucasus.

The CAR is one of the tectonic elements formed in Anatolia and taking place between the western extension and eastern pressure regimes. The CAR has approximately NS and NNE-SSW shortening, and this shortening is related to the collisional movements between the African and Anatolian plates along the Cyprian arc (Bozkurt 2001). The main tectonic elements in the CAR can be given as the Tuzgölü Fault Zone (TFZ), Central Anatolian Fault Zone (CAFZ), Akpınar fault (AF), Niğde fault (NF), and Salanda fault (SF). However, the study region is bordered by the NAFZ, Taşova-Çorum Fault Zone (TÇFZ) and Yağmurlu-Ezinepazarı Fault Zone (YEFZ) in the north, Akşehir-Afyon Graben (AAG), Akşehir Fault Zone (AFZ) and Beyşehir Graben (BG) in the west, Yakapınar-Göksun Fault Zone (YGFZ) and DSFZ in the southeast, and EAFZ and Sürgü fault (SRF) in the east (Fig. 1b). These structures in the extensional study region are characterized by oblique-slip faults, mostly dextral and sinistral strike-slip faults. The CAR is an intraplate region of the Anatolian plate to the south of the NAFZ and is generally accepted as a stable intraplate region without important crustal deformation (Özmen 2015). Neotectonics of the CAR occur between the North and East Anatolian mega shear zones, and this situation is regarded as a tectonic escape (Aktuğ et al. 2013). Reilinger et al. (1997) stated that recent seismotectonic structure of the CAR formed as a result of the convergence of the 
African and Arabian plates relative to the Anatolian plate. The CAR is described by northeast-southwest trending strike-slip fault splays bifurcating from the NAFZ, and tectonic structures are shaped with the concave geometry of the NAFZ along its western progress (Emre et al. 2018). Thus, the study area encompasses the main parts of the Anatolian plate, NAFZ, EAFZ, and DSFZ (Figs. 1a and 1c). As stated above, the CAR has not been struck with devastat- ing earthquakes in recent years in the short and intermediate term but this situation is not independent in tectonic terms. However, as indicated by the recent earthquakes, the CAR seems seismically and tectonically active. Therefore, seismic activity in the CAR is related to other tectonic regimes of Turkey (one can find all seismic and tectonic details for this region in different studies as Bozkurt 2001; Özsayın, Dirik 2007; Gökten, Varol 2010).
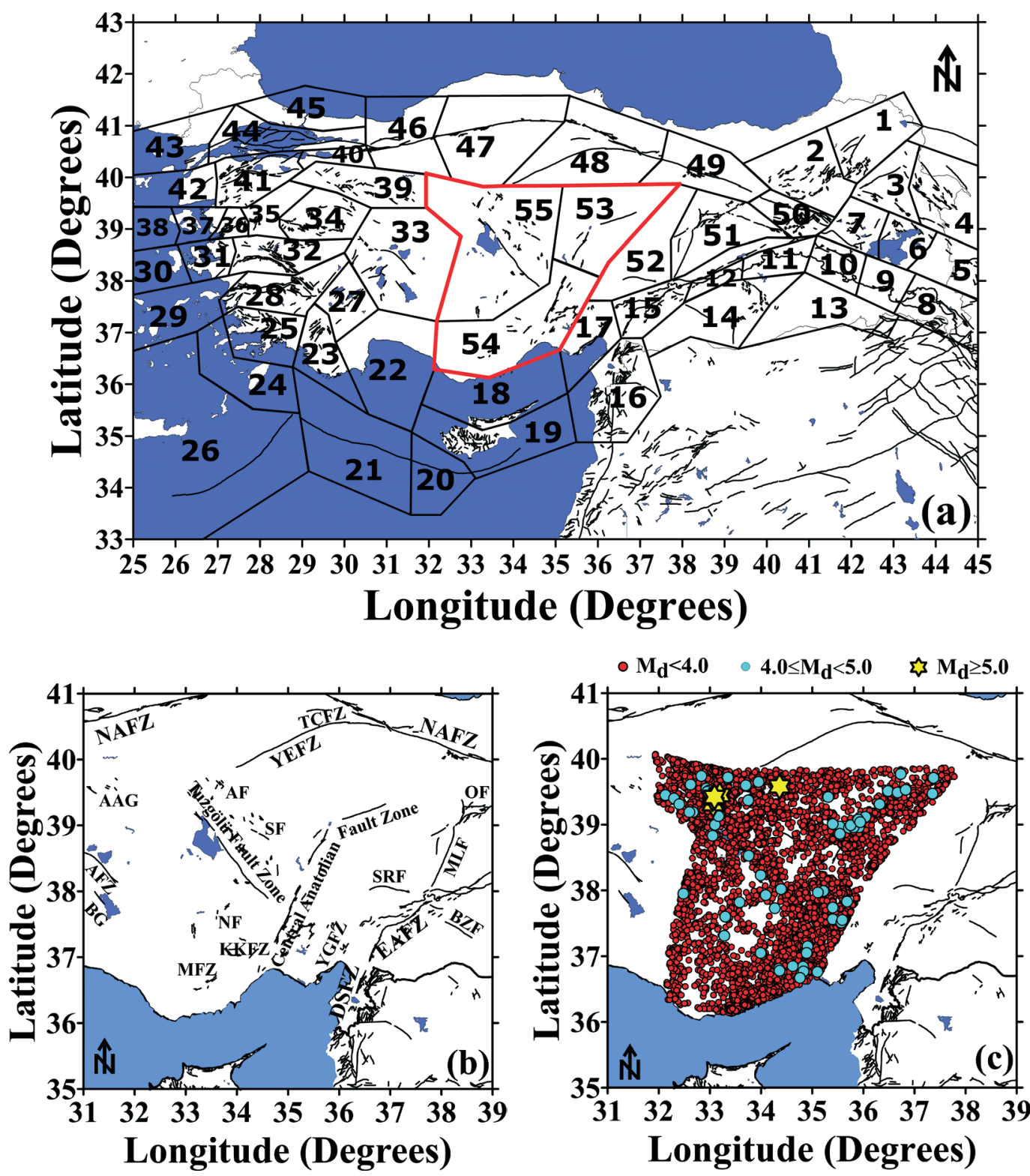

Fig 1 a) Seismotectonic sub-regions in and around Turkey including the main fault systems and zones (modified from Öztürk 2012). The area with red line shows the study region. b) Simplified tectonics in Central Anatolia and its surroundings. Tectonic environments were replaced from Şaroğlu et al. (1992), Bozkurt (2001) and Ulusay et al. (2004). Names of faults: NAFZ - North Anatolian Fault Zone, TÇFZ - Taşova-Çorum Fault Zone, YEFZ - Yağmurlu-Ezinepazarı Fault Zone, AAG - Akşehir-Afyon Graben, AFZ - Akşehir Fault Zone, BG - Beyşehir Graben, AF - Akpınar fault, NF - Niğde fault, KKFZ - Karsantı-Karaisalı Fault Zone, MFZ - Mut Fault Zone, SF - Salanda fault, YGFZ - Yakapınar-Göksun Fault Zone, SRF - Sürgü fault, DSFZ - Dead Sea Fault Zone, EAFZ - East Anatolian Fault Zone, BZF - Bozova fault, MLF - Malatya fault, OF - Ovacik fault. c) Epicentre distributions of 10,146 earthquakes in the CAR of Turkey. All events with $M_{d} \geq 1.0$ between 1975 and 2019 were plotted. Different symbols were used to show different magnitude sizes, and stars show strong/large earthquakes with $M_{d} \geq 5.0$ 


\section{METHODOLOGIES OF RESEARCH}

The statistical properties of earthquake occurrences in the CAR of Turkey were defined by analyzing and discussing the spatio-temporal changes of the most frequently used seismotectonic tools explained below.

\section{The $b$-value of frequency-magnitude distribution and magnitude completeness (Mcomp)}

As a power-law size distribution of earthquakes, the empirical relationship for the frequency-magnitude distribution was defined by Gutenberg and Richter (1944):

$$
\log _{10} N(M)=a-b M
$$

Here, $N(M)$ is the expected number of earthquakes during a specific time period with magnitudes larger than or equal to $M$. The slope of the frequency-magnitude distribution gives $b$-value, whereas $a$-value shows the seismic activity level. The $a$-value exhibits considerable variations for different areas and these changes depend on the length of the considered region, time interval of the catalogue as well as the number of earthquakes. Utsu (1971) stated that $b$-value changes between 0.3 and 2.0 in different seismic parts of the earth. However, an average of $b$-value in the G-R relation equals approximately 1.0 (Frohlich, Davis 1993). Although the $b$-value is related to the relative numbers of small and large events, there are many factors causing changes in $b$-value. Laboratory studies on rock fractures show that a decrease in $b$ value is associated with an increase in shear stress and a reduction in restricted compression. In addition, crack density, thermal gradient, geological complexity, fault length, material properties, slip distribution and strain circumstances lead to changes in $b$-value (Mogi 1962; Scholz 1968). Thus, the $b$-value is one of the major arguments for rheological-geotechnical properties and it is scale invariant.

The use of maximum earthquake data is quite significant and necessary for high quality and reliable results in the statistical seismicity studies. Therefore, analyzing of magnitude completeness, Mcomp, must be thought as the first step before statistical calculations. Mcomp is an important parameter in the estimation of $b$-value and can be calculated from the G-R distribution against magnitude (Wiemer, Wyss 2000). Mcomp is the minimum magnitude of complete recording, and $90 \%$ of the events in the catalogue are included in this magnitude level (Habermann 1983). In order to observe the changes in Mcomp, a moving time window approach (Wiemer, Wyss 2000) is generally preferred and temporal changes of Mcomp can be analyzed safely and rapidly. Since Mcomp ex- hibits systematically temporal variations, choosing incorrect Mcomp will cause wrong evaluations of the statistical earthquake parameters. If high Mcomp are removed from the database, the minimum magnitude value may be reduced and earthquake numbers used for the analyses may be increased. Thus, the knowledge of temporal Mcomp is very important and since Mcomp was used in some calculations, especially in the investigation of seismic quiescence and frequency-magnitude distribution, the estimation of Мсотp time variations was achieved carefully as a first step.

\section{Fractal analysis of earthquake distributions (Dc- value)}

The fractal dimension or correlation dimension measures the geometry of distribution and is a real number. It most probably changes in space and time, and therefore earthquake distributions are thought to be fractal, but not directly. In order to analyze the clustering features of seismicity parameters, the fractal analysis and so the two-point correlation dimension, $D c$-value, is generally used to quantify the self-similarity of a geometrical object. Grassberger and Procaccia (1983) developed an algorithm based on the distance between point pairs, and this analysis model is one of the most frequently preferred. The fractal dimension, $D c$, and the correlation sum, $C(r)$, were defined by Grassberger and Procaccia (1983) as follows:

$$
\begin{gathered}
D c=\lim _{r \rightarrow 0}[\log C(r) / \log r] \\
C(r)=2 N_{R<r} / N(N-1)
\end{gathered}
$$

Here, $C(r)$ is the correlation function, $r$ is the distance between two epicentres, and $N$ is the number of earthquake pairs separated by a distance $R<r$. If the epicentre distribution has a fractal structure, the following equation can be written:

$$
C(r) \sim r^{D C}
$$

where $D c$ is a fractal dimension, more generally, the correlation dimension. The distance $r$ (in degrees) between two events can be calculated from:

$$
\begin{gathered}
r=\cos ^{-1}\left(\cos \theta_{i} \cos \theta_{j}+\right. \\
\left.+\sin \theta_{i} \sin \theta_{j} \cos \left(\phi_{i}-\phi_{j}\right)\right)
\end{gathered}
$$

Here, $\left(\theta_{\mathrm{i}}, \varphi_{\mathrm{i}}\right)$ and $\left(\theta_{\mathrm{j}}, \varphi_{\mathrm{j}}\right)$ are the latitudes and longitudes of the $i^{\text {th }}$ and $j^{\text {th }}$ events, respectively (Hirata 1989). The $D c$-value is calculated from the slop of the graph of plotting $C(r)$ versus $r$ on a double logarithmic scale. $C(r)$ is not influenced by the lack of points outside the cluster when $r$ is small. Thus, $C(r)$ will increase fast with $r$ and $D c$ being large. Also, when a scaling range using low values of $r$ is preferred to estimate $D c$, strong clustering will follow an increase in 
$D c$. If $r$ is close to the diameter of the cluster, the rate at which $C(r)$ increases with $r$ reduces and $D c$ will be small. Therefore, if a scaling range using great values of $r$ is preferred to compute $D c$, strong clustering will follow a decrease in $r$. This signifies that, depending on the size of $r$ considered, a dense cluster of points can give both large and small $D c$.

The nature of space-time fractal features of earthquake distributions is described with fractal dimension, and therefore earthquake distributions follow fractal statistics. Fractal dimension also characterizes the self-similarity of earthquake distributions, and hence fractal distributions are practicable to scale invariant events. The $D c$-value may also be computed to describe the potential unbroken regions, and these unbroken segments can be thought as possible seismic gaps to be broken in the next (Kagan 2007). The changes in fractal properties are mostly associated with the quantitative measure or complexity of the heterogeneity degree of seismicity on the fault regimes. In the segments having an increasing complexity on the active fault regimes, a large $D c$-value is related to a small $b$-value and this is a dominant structural feature. Consequently, these variations on fractal dimension may depend on the clusters of events and may also be a sign of stress distributions on fault regimes (Öncel, Wilson 2002; Polat et al. 2008; Öztürk, Şahin 2019).

\section{Elimination of dependent events from the catalogue (declustering process) and the standard normal deviate $Z$-test (precursory quiescence, $Z$-value)}

Some secondary events such as foreshocks, aftershocks or earthquake swarms frequently increase the space-time distributions of earthquakes and thus related earthquake statistics. Therefore, all dependent activities should be removed from the catalogue to achieve a quantitative seismicity analysis. Arabasz, Hill (1996) explained that cluster analysis process "declusters" or decomposes a catalogue into primary and secondary events. This declustering process eliminates all dependent earthquakes from each cluster, and all dependent events are replaced as a single earthquake. The removal of dependent earthquakes from a catalogue is a very significant step for reliable and high quality seismicity rate changes analyses. In this work, Reasenberg (1985) technique was preferred in order to decluster the catalogue through the ZMAP software (Wiemer 2001), and dependent earthquakes were removed from independent ones. The ZMAP software was introduced by Wiemer (2001) and has been used for the declustering technique based on the algorithm modelled by Reasenberg (1985). A large number of assessments of seismicity rate changes by using the $Z M A P$ and different techniques can be found in literature after Wiemer (2001), such as Console et al. (2000), Wyss et al. (2004), Polat et al. (2008), Öztürk (2011, 2013), Talebi et al. (2015), Puangjaktha, Pailoplee (2018), Gentili et al. (2019).

In this work, the earthquake catalogue was declustered by preferring Reasenberg (1985) technique, and this declustered catalogue was preferred to map the regional distributions of seismotectonic parameters such as $b$-value, $Z$-value and recurrence time. There are 10,146 earthquakes in the catalogue, with magnitudes equal to or larger than 1.0 between 1975 and 2019. Using the declustering method, 1165 (about $11.48 \%$ ) events were removed and 8981 events remained. For the original catalogue including all shallow earthquakes with $M_{d} \geq 1.0$, the average Mcomp was estimated as 2.6. The number of events with magnitude $M_{d}<2.6$ was 5254, and all earthquakes with magnitude $M_{d}<2.6$ were eliminated from the catalogue. Finally, after declustering and eliminating $M_{d}<2.6$ earthquakes, about $63.27 \%$ of all events were separated. The number of events for seismicity analyses was reduced to 3727 , and this more homogeneous, reliable and robust catalogue was used as the final data.

There are many statistical models in order to identify and evaluate seismicity rate changes, and many of them use spatial and temporal modelling of seismic quiescence before the main events. One of the most preferred techniques for these types of studies can be given as the standard normal deviate $Z$-test. The $Z M A P$ algorithm is used to map the regions showing seismic quiescence (for details see Wiemer, Wyss 1994). Standard normal deviate $Z$-test generates the Long Term Average, LTA $(t)$, function for the statistical assessment of the confidence level in standard deviation units:

$$
Z(t)=\frac{R_{1}-R_{2}}{\left(\frac{\sigma_{1}^{2}}{n_{1}}+\frac{\sigma^{2}{ }_{2}}{n_{2}}\right)^{1 / 2}}
$$

where $R_{l}$ is the average number of earthquakes in the foreground window, $R_{2}$ is the average seismic activity rate in the whole background period, and $\sigma$ and $n$ are standard deviations and the number of samples within and outside the window. The $Z$-value calculated as a function of time lets the foreground window slide along the duration of the catalogue and is named as $\operatorname{LTA}(t)$.

\section{RESULTS}

A comprehensive statistical study was carried out for the CAR of Turkey, one of the four significant tectonic zones of Anatolia, by evaluating the most 
frequently used seismic and tectonic parameters mentioned above. In order to describe the statistical behaviours of seismic activity, the histograms of the region-time-magnitude distributions of earthquakes were mapped for the beginning of 2019. All statistical parameters were calculated and plotted with ZMAP. For the calculation of $b$-value, the maximum likelihood estimation was preferred since it provides a stronger estimate than that of the least-square regression method (Aki 1965). However, for the estimation of $D c$-value, $95 \%$ confidence limits by linear regression were used since this is given as the most suitable technique by the aforementioned researchers.

In order to realize the analyses in this study, the magnitude completeness of the catalogue was estimated as the first step. Since regional and temporal Mcomp generally have non-stable values, the calculation of Mcomp is the first and the most important stage. In fact, the main goal of this type of calculation is to have the maximum number of events for high reliability conclusions in seismological studies. As stated in Woessner, Wiemer (2005), temporal changes in Mcomp can be observed with a moving time window method with the maximum curvature technique. As a first step, a certain number of earthquakes per window are taken into account and an average magnitude value is calculated for this earthquake sequence. Then, this value calculated for each window is accepted as the average Mcomp value for the time interval which covers that window. Therefore, the estimation of Mcomp is made as a function of time with the maximum curative method by using an overlapping moving window technique. In this work, the original catalogue including 10,146 earthquakes with $M_{d} \geq 1.0$ was considered and Mcomp was plotted with its standard deviation for every 200 earthquakes per window. Figure 2 shows the temporal Mcomp changes. As shown in Fig. 2, Mcomp is in and around 3.4, and relatively large changes can be seen from 3.0 to 3.6 between 1975 and 2004, whereas it generally changes between 2.0 and 2.8 from 2004 to 2014 . Then, it decreases to

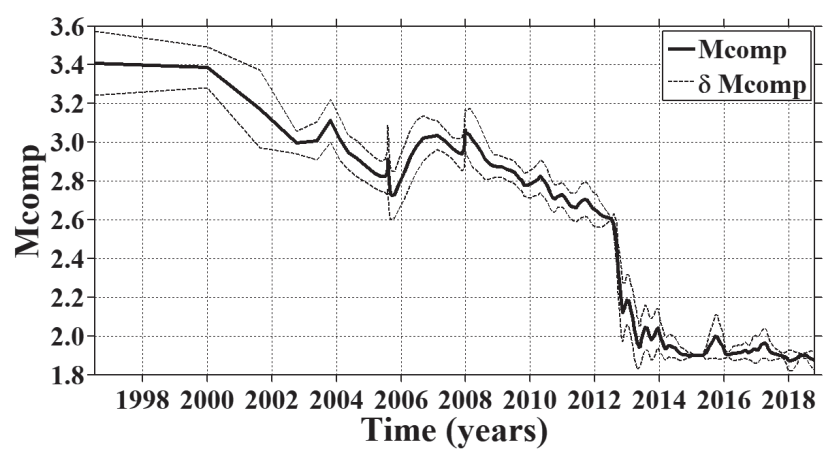

Fig. 2 Temporal changes of magnitude completeness, Mcomp, with the standard deviation, $\delta$ Mcomp. Mcomp was determined with a moving window approach, and each window includes 200 earthquakes
2.0 at the beginning of 2014 and to about 1.9 after 2014. It can clearly be seen that Mcomp changes from 2.6 to 1.9 after 2012 . Since this work includes the $b$ value and $Z$-value statistics, Mcomp estimation has a great importance. Thus, the average Mcomp for the CAR of Turkey was used as 2.6 which properly represents data, and this Mcomp level was considered for all statistical calculations in the CAR.

The cumulative number of events as a function of time for the original catalogue with $M_{d} \geq 1.0$ including 10,146 earthquakes, for the declustered catalogue with $M_{d} \geq 1.0$ comprising 8981 earthquakes, and for the declustered catalogue with $M_{d} \geq 2.6$ containing 3727 earthquakes is plotted in Fig. 3. There are no any significant fluctuations in earthquake activity between 1975 and 2000, and earthquake activity shows very little changes from 2000 to 2005 as seen from Fig. 3. However, due to the improved monitoring systems, there exist important increases in the number of earthquakes, especially starting after 2006. Time distribution of the cumulative number of declustered earthquakes with $M_{\mathrm{d}} \geq 2.6$ has a smooth slope when compared to the original catalogue. Katsumata, Kasahara (1999) and Joseph et al. (2011) suggested that magnitude completeness and declustering process are quite important to make a reliable definition of earthquake behaviours. These researchers indicated that dependent earthquakes such as foreshocks, aftershocks or swarms should be removed from the catalogue before analyses and only the main events should be used. As an important result, the declustering process and removing of $M_{\mathrm{d}}<2.6$ events from the original catalogue separated the dependent events from the catalogue (black and red arrows in Fig. 3). With the usage of these two processes, a more homogeneous, robust and reliable earthquake catalogue was obtained.

The $b$-value of the G-R distribution was calculated with the maximum likelihood technique as mentioned

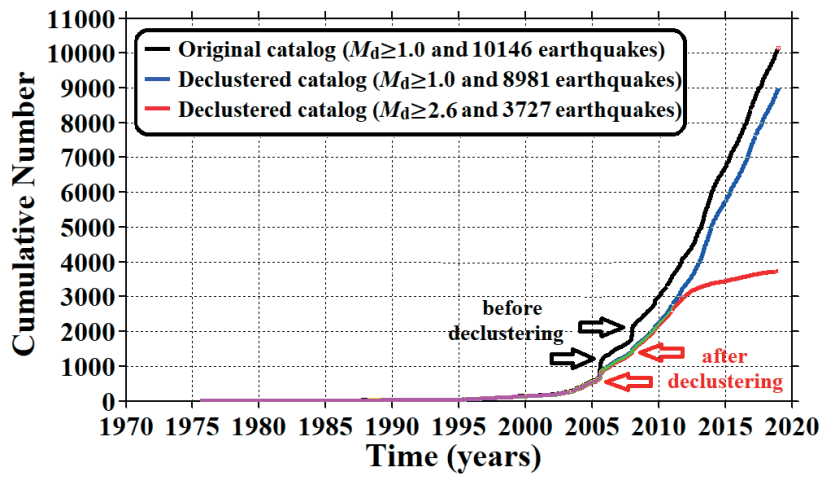

Fig. 3 Time variations of the cumulative number of earthquakes for the original catalogue with $M_{\mathrm{d}} \geq 1.0$, for the declustered catalogue with $M_{\mathrm{d}} \geq 1.0$ and for the declustered catalogue with $M_{\mathrm{d}} \geq 2.6$. The effect of declustering process was also shown after and before two dense earthquake activities 
above and shown in Fig. 4. As shown in the cumulative number of earthquakes against the magnitude of events, the average Mcomp was considered to be 2.6 for the whole catalogue including 10,146 events between 1975 and 2019, and $b$-value was calculated as $1.26 \pm 0.07$. The $b$-value, its standard deviation, $a$-value and Mcomp are also given on Fig. 4. As previously stated, $b$-value varies from 0.3 to 2.0 on a global scale and tectonic earthquakes are proposed to have a $b$-value between 0.5 and 1.5 although the average $b$-value is assumed close to 1.0. Thus, the frequency-magnitude distribution of the earthquake catalogue for the CAR matches with the G-R scaling law, and this relatively large $b$-value means that the study region has a high frequency of small or moderate events (Fig. 1c). Also, Schorlemmer et al. (2005) suggested that $b$-value changes with different fault regimes. They stated that normal fault systems have the highest $b$-values, thrust regimes the lowest, and strike-slip earthquakes intermediate values. Since thrust faults tend to be under larger stress than normal faults, they infer that the $b$-value acts as a stress meter that depends inversely on differential stress. For this reason, they pointed out that earthquake hazard analysis must be rethought by considering different faulting styles. As stated in Section 2 (main tectonics in the CAR), tectonic elements in the extensional study area are characterized by oblique-slip faults, mostly dextral and sinistral strike-slip faults. Hence, this intermediate $b$-value calculated for the CAR may be commented as a large heterogeneity and low stress distribution in the study region.

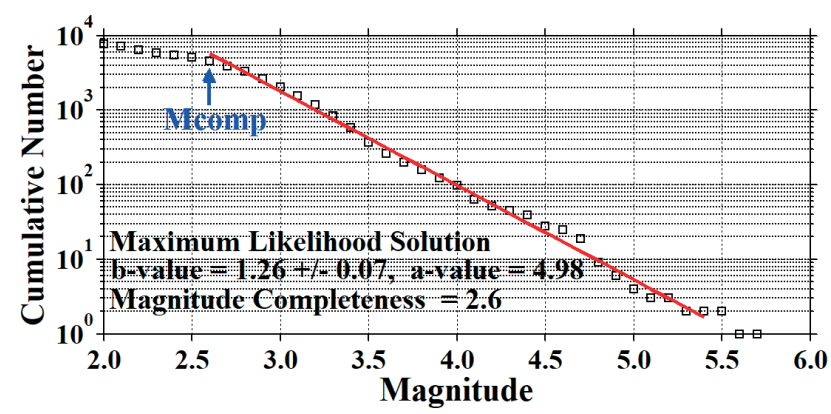

Fig. 4 The $b$-value of Gutenberg-Richter frequency-magnitude distribution estimated with the maximum likelihood approach. $b$-value, its standard deviation, $a$-value and Mcomp are also included on the figure

Figure 5 shows the fractal statistic of the events in the CAR. Estimation of the fractal dimension of earthquake epicentres was made by fitting a straight line to the correlation integral curve, $C(R)$, against the earthquake distance $R(\mathrm{~km})$, in other words, log $C(r)$ versus $\log r$. The $D c$-value was estimated as $1.31 \pm 0.03$ for 10,146 epicentre distributions with a $95 \%$ confidence limit by using linear regression. There exists an obvious linear interval and scale in- variance in the cumulative statistic between 5.03 and $81.09 \mathrm{~km}$. As shown in Fig. 5, standard deviation was also calculated within these distances and shown on the figure. As described earlier, earthquake distributions are compatible with the fractal dimension, and therefore they match the fractal statistics. It is well known that larger $D c$-values are related with active faults and these fault systems have an increasing complexity. Conversely, a smaller fractal dimension is related to the rate at which the correlation integral increases. Also, small $D c$-values are observed if distance between two epicentres is close to the diameter of the cluster (Öncel, Wilson 2002). This means that earthquake activity has a relatively strong clustering at smaller scales (or in larger areas) in the CAR. This relatively smaller $D c$-value is also a dominant structural characteristic in this area and may depend on the range of chosen distance. As a remarkable fact, it can also be an indication of small stress relaxation in the study region.

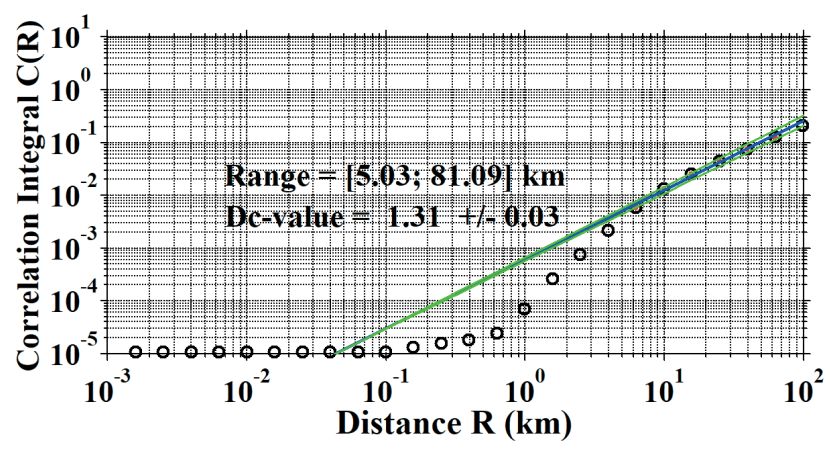

Fig. 5 Estimation of the fractal dimension of earthquake epicentres. By fitting a straight line to the correlation integral curve, $C(R)$, versus earthquake distance, $R(\mathrm{~km})$, $D c$-value was calculated with a $95 \%$ confidence limit in the cumulative statistic between 5.03 and $81.09 \mathrm{~km}$. The slope of the blue line corresponds to $D c$-value, and green line indicates the standard error

Primary applications in the definition of the statistical behaviours of earthquake occurrences must include the annual probabilities and recurrence times of strong/large earthquake magnitudes. Therefore, this study consists of these types of analyses and the results of annual probabilities and recurrence times for different magnitude sizes are mapped in Fig. 6. The annual probabilities of earthquake distributions have the values from 1 to 30 (relatively large) for the magnitude sizes from 3.0 to 4.4 , and the values lower than 1 for the magnitude sizes between 4.4 and 6.0 (Fig. 6a). Fig. $6 \mathrm{~b}$ shows the recurrence times of earthquake distributions for different earthquake magnitudes. Relatively smaller recurrence time intervals $(<1.0)$ were estimated for the magnitudes between 3.0 and 4.4, and the time intervals between 1 and 5 years for the earthquake magnitudes from 4.4 to 5.0. In addition, the values between 5 and 20 years can be expected for 

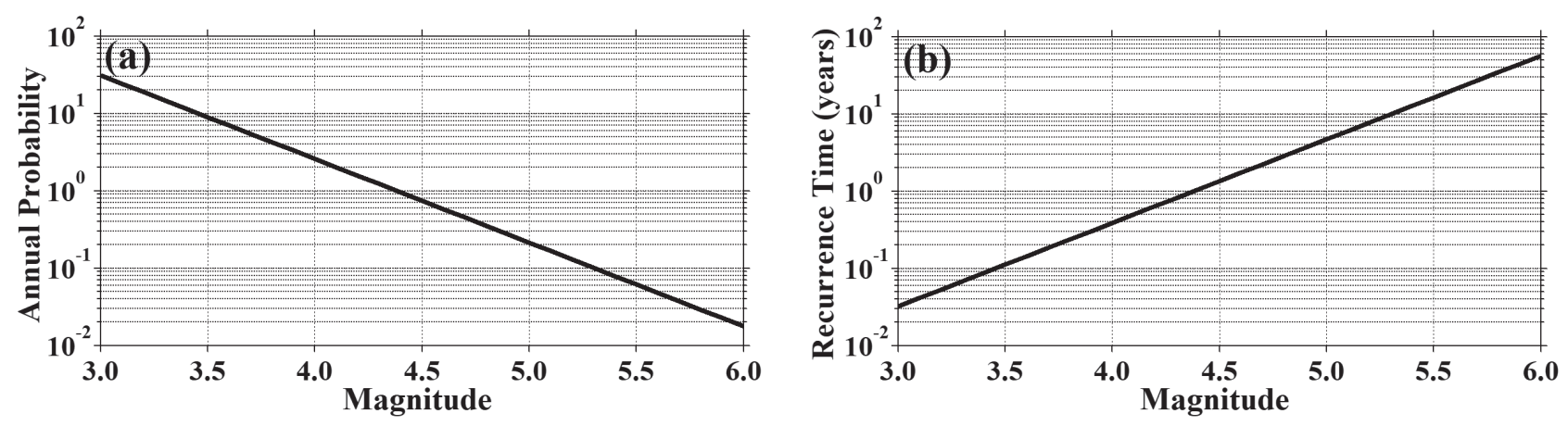

Fig. 6 a) Annual probabilities and b) recurrence times for different magnitude sizes of earthquake occurrences in the CAR

the magnitude ranges between 5.0 and 5.6, whereas the values from 20 to 60 years can be considered for the magnitude levels greater than 6.0. As cited above, several strong/large earthquakes occurred in the CAR in the past and recent years: Bala-Ankara on 4 July 1978 (M5.3), Bala-Ankara on 21 April 1983 (M5.0), Bala-Ankara on 20 December $2007(M=5.7)$, BalaAnkara on 27 December $2007(M=5.5)$, Hacidurakl1Kirşehir on 10 January $2016(M=5.1)$ and Bor-Niğde on 20 September 2020 (M5.1). Joseph et al. (2011) suggested that the earthquake catalogue must be declustered and a completeness analysis must be done for the statistical evaluation of earthquake behaviours, especially in the recurrence time analyses of earthquakes. For this reason, a declustered earthquake catalogue was used in these estimations. The results of analyses of annual probabilities and recurrence times suggest the existing seismic potential in the CAR. As a remarkable fact, the CAR has an intermediate/longterm seismic potential after 2021 for the possibility of strong/large earthquake occurrence $\left(M_{d} \geq 5.0\right)$ according to the probabilities and recurrence times of earthquake occurrences at this selected magnitude levels.

In order to make a temporal evaluation of earthquake activity, statistical earthquake parameters such as $b$-value, $D c$-value, Mcomp and $a$-value as well as earthquake numbers, minimum $\left(M_{\min }\right)$ and maximum $\left(M_{\max }\right)$ magnitude were calculated for every year, excluding from 1975 to 2002 . The results are given in Table 1. Although there were no many large earthquakes, five strong/large earthquakes greater than or equal to 5.0 occurred between 1975 and 2016. The characteristic of temporal clustering which is related to stronger/larger earthquakes appears to be strong enough for many earthquakes that occurred between $1998\left(M_{d} 4.6\right)$ and $1999\left(M_{d} 4.8\right)$, in $2004\left(M_{d} 4.4\right), 2005$ $\left(M_{d} 4.9\right), 2007\left(M_{d} 5.7\right), 2011$ (M 4.4$), 2014$ (M 4.1$)$, and $2016\left(M_{d} 5.1\right)$. The variations of $b$-value and $D c$ value in time were analyzed to measure and evaluate the temporal fluctuations between 1975 and 2019, and these changes are plotted in Fig. 7. Estimations were not performed for every year since the number of earthquakes between 1975 and 2002 was very low.
As seen in Fig. 7, $b$-values are in a clear decreasing trend whereas $D c$-values have a clear increasing trend in the same years. These decreases and increases can also obviously be seen in Table 1 and from the arrows drawn on Fig. 7. For example, the $b$-value shows a clear decrease while the $D c$-value shows a clear increase from 1997 to 1999, and stronger events occurred between 1998 and 1999 than in 1997. As shown in Table 1 from rectangular areas, these types of similar decreases and increases were also recorded between 2003 and 2004, 2004 and 2005, 2006 and 2007, 2010 and 2011, 2013 and 2014, and 2015 and 2016. As previously mentioned, there are many factors affecting these decreases and increases. Smaller $b$-values are related to larger $D c$-values in active fault systems, and a larger order of the $D c$-value is very sensitive to heterogeneity in magnitude distributions. This means that seismicity is more clustered in smaller areas (or at larger scales) in the time intervals when larger $D c$-values were observed. These changes in $b$ and $D c$-values can also be an indication of relative stress changes in these time intervals. As a remarkable fact, these variations mean that observation of these types of fluctuations in $b$ and $D c$-values may supply preliminary and useful evidences for the evaluation of future earthquake potential in the intermediate/long term in the CAR of Turkey.

Regional changes in the $b$-value were mapped by using a mowing window technique in the $Z M A P$ with

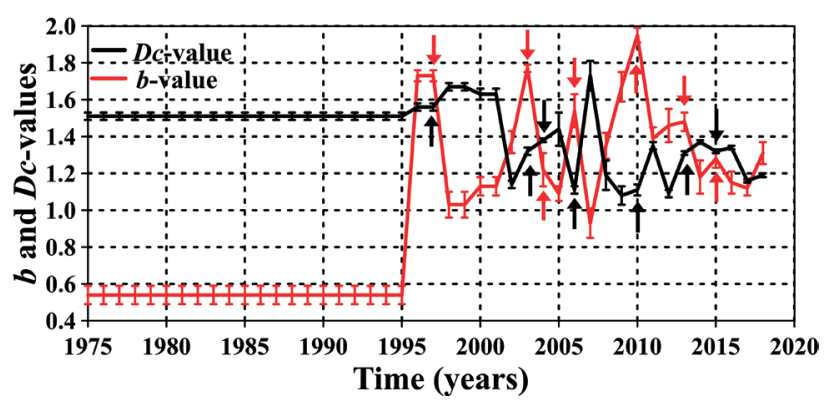

Fig. 7 Temporal variations in $b$-value and $D c$-value between 1975 and 2019. Black and red arrows indicate the beginning times of increases in $D c$-value and the beginning times of decreases in $b$-value, respectively 
Table 1 Changes in seismicity parameters such as the number of events, minimum $\left(M_{\min }\right)$ and maximum $\left(M_{\max }\right)$ magnitudes, $M c o m p, a$-values, $b$-values, $D c$-values and size ranges $(\mathrm{km})$ for the Central Anatolian part of Turkey from 1975 to 2019. Rectangular areas show the decreases in $b$-value and increases in $D c$-value in the consecutive years and hence the occurrences of strong earthquakes in these years

\begin{tabular}{|c|c|c|c|c|c|c|c|c|}
\hline Year & Number of earthquakes & $M_{\min }$ & $M_{\max }$ & Mcomp & $a$-value & $b$-value & $D c$-value & Size ranges $(\mathrm{km})$ \\
\hline $1975-1995$ & 54 & 1.8 & 5.3 & 3.3 & 3.42 & $0.54 \pm 0.05$ & $1.51 \pm 0.02$ & $5.03-90.40$ \\
\hline $1996-1997$ & 46 & 2.7 & 3.8 & 3.3 & 7.53 & $1.73 \pm 0.03$ & $1.56 \pm 0.02$ & $5.88-99.23$ \\
\hline $1998-1999$ & 46 & 2.7 & 4.8 & 3.4 & 5.17 & $1.03 \pm 0.07$ & $1.67 \pm 0.02$ & $5.11-39.08$ \\
\hline $2000-2001$ & 42 & 2.4 & 4.2 & 3.3 & 5.16 & $1.13 \pm 0.05$ & $1.63 \pm 0.03$ & $5.19-91.81$ \\
\hline 2002 & 68 & 2.0 & 4.1 & 3.2 & 5.98 & $1.37 \pm 0.06$ & $1.14 \pm 0.02$ & $5.11-82.36$ \\
\hline 2003 & 121 & 2.3 & 4.0 & 3.0 & 7.14 & $1.77 \pm 0.02$ & $1.32 \pm 0.02$ & $5.11-99.23$ \\
\hline 2004 & 193 & 2.1 & 4.4 & 2.8 & 5.62 & $1.22 \pm 0.09$ & $1.38 \pm 0.01$ & $5.16-57.62$ \\
\hline 2005 & 712 & 2.5 & 4.9 & 2.7 & 5.73 & $1.09 \pm 0.04$ & $1.44 \pm 0.09$ & $5.11-22.70$ \\
\hline 2006 & 250 & 2.5 & 4.0 & 3.0 & 6.87 & $1.54 \pm 0.09$ & $1.11 \pm 0.02$ & $5.03-91.81$ \\
\hline 2007 & 504 & 2.5 & 5.7 & 3.0 & 6.89 & $0.93 \pm 0.08$ & $1.73 \pm 0.08$ & $5.24-15.39$ \\
\hline 2008 & 459 & 2.5 & 4.8 & 2.9 & 6.43 & $1.35 \pm 0.07$ & $1.19 \pm 0.08$ & $5.03-28.65$ \\
\hline 2009 & 496 & 2.4 & 4.4 & 2.8 & 7.20 & $1.67 \pm 0.08$ & $1.08 \pm 0.05$ & $5.11-34.52$ \\
\hline 2010 & 578 & 2.1 & 4.1 & 2.8 & 7.92 & $1.95 \pm 0.08$ & $1.11 \pm 0.03$ & $5.11-90.40$ \\
\hline 2011 & 609 & 1.6 & 4.4 & 2.6 & 6.17 & $1.39 \pm 0.06$ & $1.35 \pm 0.02$ & $5.03-96.19$ \\
\hline 2012 & 682 & 1.5 & 4.4 & 2.6 & 6.15 & $1.46 \pm 0.09$ & $1.09 \pm 0.02$ & $5.03-94.71$ \\
\hline 2013 & 1155 & 1.3 & 3.6 & 2.0 & 4.91 & $1.48 \pm 0.05$ & $1.31 \pm 0.01$ & $5.03-96.19$ \\
\hline 2014 & 694 & 1.3 & 4.1 & 1.9 & 4.83 & $1.18 \pm 0.09$ & $1.37 \pm 0.01$ & $5.11-61.32$ \\
\hline 2015 & 798 & 1.0 & 3.9 & 1.9 & 4.80 & $1.28 \pm 0.05$ & $1.32 \pm 0.01$ & $5.03-94.71$ \\
\hline 2016 & 973 & 1.3 & 5.1 & 1.9 & 4.86 & $1.15 \pm 0.06$ & $1.34 \pm 0.01$ & $5.03-90.40$ \\
\hline 2017 & 886 & 1.1 & 3.7 & 1.9 & 4.83 & $1.12 \pm 0.04$ & $1.16 \pm 0.01$ & $5.03-93.25$ \\
\hline 2018 & 780 & 1.0 & 3.8 & 1.9 & 5.01 & $1.31 \pm 0.06$ & $1.19 \pm 0.01$ & $5.03-94.71$ \\
\hline
\end{tabular}

a sample of 750 events per window and prepared by a spatial grid of $0.08^{\circ} \times 0.08^{\circ}$ in latitude and longitude. A declustered earthquake catalogue with $M_{d} \geq$ 2.6 (3727 events) was used for this calculation. As seen in Fig. 8, regional distribution of the $b$-value changes between 0.5 and 1.9. As stated in Frohlich and Davis (1993), the $b$-value of earthquake distributions is well represented by the G-R relation with an average value of $b=1.0$. Depending on this statement, the areas with the largest $b$-values $(>1.5)$ were

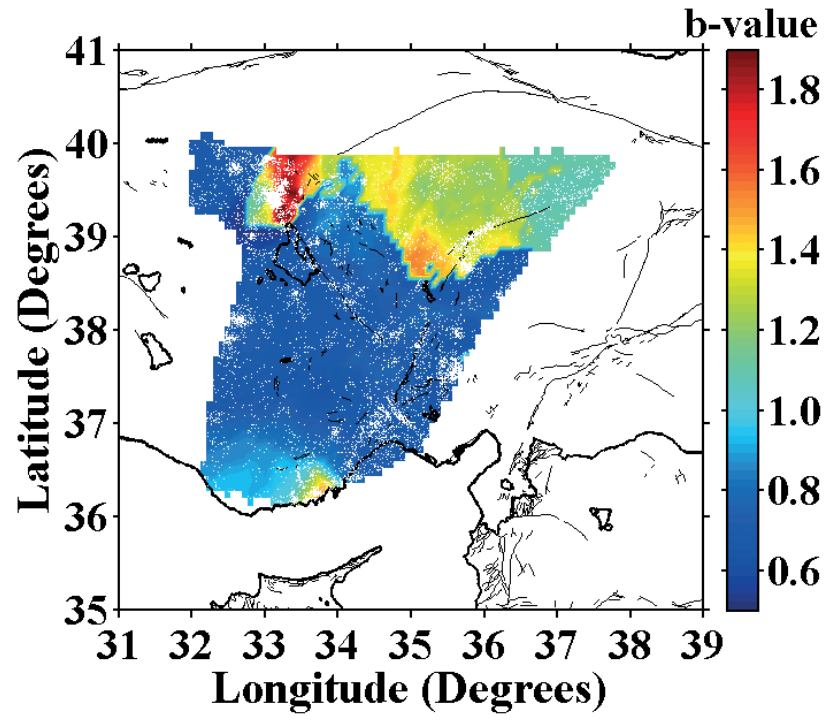

Fig. 8 Regional changes in $b$-value for the CAR of Turkey. White dots show declustered earthquakes with $M_{d} \geq 2.6$ observed in and around $\mathrm{AF}$ and in the northwest end of TFZ, whereas other larger values $(1.0<b<1.5)$ were found in the north-eastern parts of the study region including the northwest segment of the CAFZ. However, the regions with the smallest $b$-values $(<$ 0.8 ) were generally observed in all parts of the CAR including the north-western end of the study region, along the TFZ, SF, NF and throughout the southwestern parts of the CAFZ, while other smaller values $(0.8<b<1.0)$ were calculated in the southwestern part of the CAR (Fig. 8). The areas with larger $b$-values have generally a larger proportion of small-magnitude events (Fig. 1c). However, the areas with lower $b$-values represent the regions in which great-magnitude events occur more often. In several parts of the CAR, relatively great $b$-values were computed and it can be evaluated that the stress in these regions is more easily decreased with a great number of small-magnitude events. Thus, this situation can be interpreted as a large heterogeneity (Polat et al. 2008) and low stress release because of a high heat flow. It is accepted that smaller $b$-values make a sign of a higher stress release. Therefore, the smallest $b$ values may be an evidence of a low heterogeneity degree and high strain due to the active tectonics of the CAR. These low $b$-values can also be related to the stress to build up over time and to be released by earthquakes that are less frequent but large in magnitude (Öncel, Wilson 2002). As stated in many studies in literature, small $b$-values may show the areas in 
which the next possible earthquake will occur. Thus, a low $b$-value can be used to forecast the location of future earthquakes in these regions. However, in the areas with large $b$-values, this situation may be interpreted as an indication of low stress relaxation by a great number of small events, and thus there is a very high geological complexity in these regions. As an important finding, the $b$-values estimated with the maximum likelihood method from the G-R relation exhibit a good correlation to seismotectonic environment. Therefore, special attention should be paid to these areas of the CAR with small $b$-values.

Another significant application in the characterization of the statistical properties of earthquake behaviours covers the investigation of precursory seismic quiescence revealing the earthquake activity rate. For this reason, the regional change of the standard normal deviate $Z$-value was mapped for the beginning of 2019 in the CAR. For this purpose, the study area was divided into regional grids of points with a size of $0.08^{\circ} \times 0.08^{\circ}$ in latitude and longitude. The nearest earthquakes, $N$ at each node, were considered as 50 earthquakes. Earthquakes distribution was binned into many binning spans of 28 days for each grid point to obtain a dense and continuous coverage in time. Time window length, $T_{W}$, is preferred as 4.5 years because the quiescence areas are better visible for this time window. In order to map the geographical changes of the standard normal deviate $Z$-value at the beginning of 2019, the declustered data with $M_{d} \geq 2.6$ (3727 events) was used. Regional changes in $Z$-value in the CAR are displayed in Fig. 9. By adding $T_{W}$-value to the chosen time as the beginning of the "cut at" time, the time window length for the $Z$-value image was obtained and this time is shown at the top of the figure. As shown in Fig. 9, there are six regions exhibiting precursory quiescence anomalies at the beginning of 2019. These anomaly regions were centred at: $(i)$ $39.48^{\circ} \mathrm{N}-32.63^{\circ} \mathrm{E}$ (region $\mathrm{A}$, northwest ends of the $\mathrm{TFZ}$ and study region), (ii) $39.13^{\circ} \mathrm{N}-35.18^{\circ} \mathrm{E}$ (region $\mathrm{B}$, northeast of the SF, and between the SF and the CAFZ), (iii) $38.76^{\circ} \mathrm{N}-36.01^{\circ} \mathrm{E}$ (region $\mathrm{C}$, northeast parts of the CAFZ), (iv) $38.14^{\circ} \mathrm{N}-32.72^{\circ} \mathrm{E}$ (region $\mathrm{D}$, southwest of Tuzgölü), (v) $37.85^{\circ} \mathrm{N}-34.59^{\circ} \mathrm{E}$ (region $\mathrm{E}$, southeast end of the TFZ between the TFZ and the CAFZ), and (vi) $37.24^{\circ} \mathrm{N}-35.34^{\circ} \mathrm{E}$ (region F, between the CAFZ and YGFZ). For this reason, spatial emphasis should be given to these quiescence regions. Consequently, the regional distribution of the $Z$-value can make important contributions for the evaluation of the seismicity rate changes, and reliable precursors may be useful for the characterization of statistical behaviours of earthquake occurrences in the CAR.

The regional distributions of the recurrence times for strong/large earthquakes are displayed in Fig. 10. In order to image the geographical variations of the

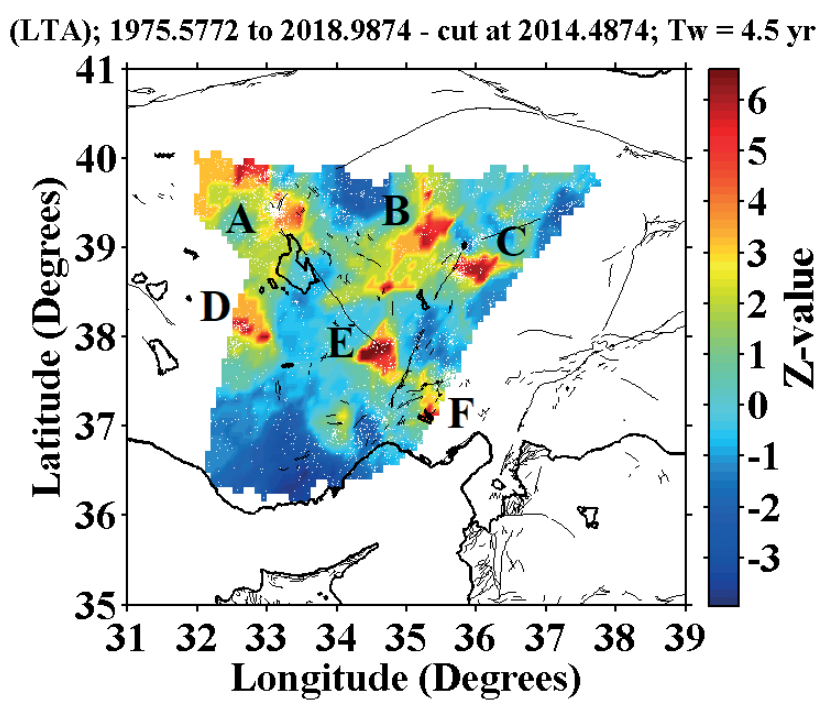

Fig. 9 Regional variations in seismic quiescence $Z$-value at the beginning of 2019 with $T_{W}=5.5$ years for the CAR. Declustered earthquakes with $M_{d} \geq 2.6$ are represented by white dots. Six anomaly regions of quiescence detected at the beginning of 2019 can be given as regions A (northwest ends of TFZ and study region), B (northeast of SF, and between SF and CAFZ), C (northeast parts of CAFZ), D (southwest of Tuzgölü), E (southeast end of TFZ between TFZ and CAFZ) and F (between CAFZ and YGFZ)

recurrence times of selected magnitude levels $\left(M_{d}=\right.$ $5.0, M_{d}=5.5$ and $M_{d}=6.0$ ) for the next years, declustered earthquakes with $M_{d} \geq 2.6$ (3727 events, as in $b$ and $Z$-values) were used. As seen in Fig. 10a, recurrence times were found to be smaller, generally changing between 3 and 12 years, for magnitude level $M_{d}=5.0$. Recurrence times between 3 and 6 years were observed in the northwest end of the TFZ and in the vicinity of the northeast parts of the CAFZ. Recurrence times change between 6 and 8 years in and around the NF and in the vicinity of the southwest parts of the CAFZ. The other regions have the recurrence times greater than 8 years for the $M_{d}=5.0$ level. Figure 10b shows the recurrence times of $M_{d}$ $=5.5$ earthquakes, varying from 5 to 22 years. The northwest end of the TFZ has the recurrence times between 5 and 10 years, whereas the vicinity of the northeast parts of the CAFZ, the vicinity of the NF and the southwest parts of the CAFZ have 10- and 15 -year recurrence times for strong earthquake occurrences. The recurrence times in the $M_{d}=5.5$ level for the rest parts of the study region show the values between 15 and 22 years. The recurrence times of $M_{d}$ $=6.0$ earthquakes are plotted in Fig. 10c. The recurrence times for this magnitude level are generally between 10 and 40 years. The northwest end of the TFZ has the recurrence times changing between 10 and 25 years, while the vicinity of the northeast parts of the CAFZ, the vicinity of the NF and the southwest parts of the CAFZ have 25- and 35-year recurrence times 

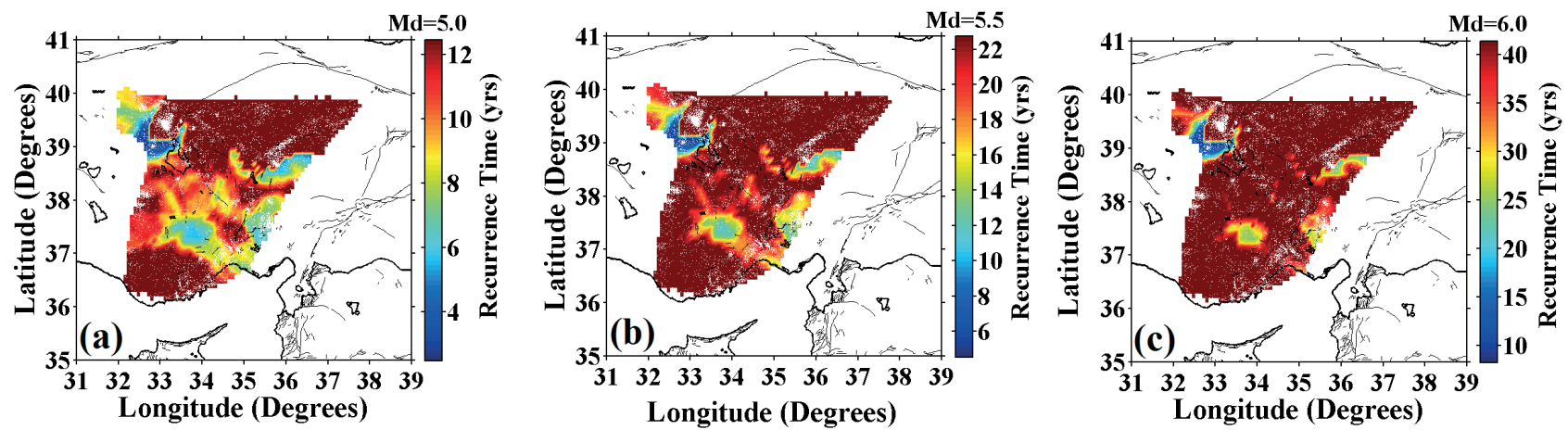

Fig. 10 Regional changes of recurrence times for selected magnitude levels including strong/large earthquakes: a) $M_{d}=$ 5.0 , b) $M_{d}=5.5$ and c) $M_{d}=6.0$. Declustered earthquakes with $M_{d} \geq 2.6$ were plotted with white dots

for the $M_{d}=6.0$ level. Other parts of the CAR have a value larger than 35 years for strong/large earthquake occurrences. As mentioned in the Introduction section, there are some strong/large earthquakes in the instrumental period. From the occurrence of these earthquakes, an average recurrence time of strong/ large earthquakes can be simply calculated as $12.6 \pm$ 10 years. As seen from Fig. 10, the recurrence times for moderate earthquakes with $M=5.0$ and $M=5.5$ change roughly between 3 and 23 years, and this result is also supported by regional variations of recurrence times given in Fig. 10. Hence, these detailed analyses on recurrence times for strong/large earthquake occurrences indicate that there exists an earthquake potential in the CAR in the intermediate/long term. Consequently, these types of estimations focused on earthquake behaviours can contribute to earthquake hazard for the near future.

\section{DISCUSSIONS}

There exist a large number of statistical studies as mentioned above on the spatio-temporal behaviours of earthquake occurrences for different parts of the world. Also, many researchers have applied different methods to present the region-time-magnitude variations of earthquake distributions for different parts of Turkey (e.g., Yüksel 1985; Dirik, Güncüoğlu 1996; Koçyiğit 2000; Bilim 2003; Çobanoğlu et al. 2006; Polat et al. 2008; Kahraman et al. 2008; Öztürk et al. 2008; Özmen 2015; Öztürk 2011, 2017, 2018). As sated before, the CAR has no important seismic potential in terms of occurrences of strong earthquakes in the short term. However, these types of assessments including the possible correlation between seismic and tectonic parameters are very few for this part of Turkey. Hence, it is aimed to make a detailed regional and temporal statistical analysis of earthquake behaviours to investigate the earthquake potential in the CAR at the beginning of 2019.

A statistical seismicity analysis of the western part of Turkey, Aegean extension region, was achieved by
Polat et al. (2008) by using different seismic and tectonic parameters such as the $b$-value of the G-R relation, fractal dimension $D c$-value, and standard normal deviate $Z$-value. They suggested an important earthquake hazard depending on these size scaling parameters and proposed that the regions of larger $Z$-values and lower $b$-values may be the most possible places for the future strong/large earthquake occurrences supporting the evidence that a decrease in $b$-value is related to an increase in stress distribution. An assessment of the seismic hazard for different parts of Turkey using Gumbel's I method was also achieved by Öztürk et al. (2008). A quantitative appraisal of several parameters such as recurrence times, possible maximum magnitude, and the possibility of a large earthquake occurrence. They achieved their analyses for different magnitude sizes in different periods such as $10,25,50$, and 100 years in different 24 regions in and around Turkey, and thus they suggested many potential regions for the occurrences of the major earthquakes in different times. In addition to these comprehensive studies, similar results of these parameters were found by Öztürk $(2011,2015,2018)$ for different parts of Turkey including the WAGS, NAFZ, EAFZ, BZTZ and NEAFZ. In these studies, successful forecasts were published for the next earthquake occurrences such as Elazığ $(M=6.0)$ on 8 March 2010, Lake Van $(M=6.6)$ on 23 October 2011, Refahiye-Erzincan $(M=5.6)$ on 22 September 2011, Gökçeada-Çanakkale $(M=5.3)$ on 30 July 2013, Kı ̆̆1-Bingöl $(M=5.5)$ on 3 December 2015, Silivri-İstanbul $(M=5.7)$ on 26 September 2019, and Pütürge-Malatya on 5 June 2020. In the present study for the CAR, the smaller $b$-values were estimated in many parts including the north-western end of the study region, along the TFZ, SF, NF, throughout the south-western parts of the CAFZ and in the southwestern part of the CAR, whereas the larger $Z$-values were found in the northwest ends of the TFZ and study region, in the northeast of the SF, and between the SF and the CAFZ, in the northeast parts of the CAFZ, in the southwest of Tuzgölü, in the southeast end of the 
TFZ between the TFZ and the CAFZ, and between the CAFZ and the YGFZ. With the combination of these two parameters, it can be interpreted that the north-western end of the study region, the southwest of Tuzgölü, the southeast end of the TFZ between the TFZ and the CAFZ, between the CAFZ and YGFZ should be suggested as significant regions of seismic hazard for possible earthquake occurrences. Thus, the evaluation of these seismotectonic parameters may supply useful preliminary evidences in the forecasting of the next earthquake locations.

Dirik and Güncüoğlu (1996) aimed to give a summary of neotectonic properties of Central Anatolia considering the recent studies and to make an evaluation of the seismicity of this region. They stated that many earthquake epicentres, thermal waters and volcanic regions show a general distribution along the main fault zones in Central Anatolia. Thus, considering morphotectonic properties and earthquake occurrences, they suggested that many segments in Central Anatolia are still tectonically active.

Bilim (2003) made a statistical analysis of earthquake hazard in Çankırı, one of the largest depocentres of Central Anatolia, by using Gumbel's first asymptotic distribution of extreme values. The earthquakes with magnitude $\mathrm{Mb} \geq 4.0$ (body wave magnitude) located at the $40.30^{\circ}-41.00^{\circ} \mathrm{N}$ latitude and $32.50^{\circ}-34.50^{\circ} \mathrm{E}$ longitude between 1964 and 2002 were used. The $b$-value of the G-R relationship was calculated as 0.56 with the maximum likelihood estimation. The probabilities of $\mathrm{Mb} \geq 5.0$ earthquake occurrences in 25, 50 and 75 years were estimated as $93 \%, 99 \%$ and $99 \%$, respectively. For $\mathrm{Mb} \geq 5.5$ earthquake occurrences in 25, 50 and 75 years, the probabilities were calculated as $77 \%, 95 \%$ and $98 \%$, respectively. However, for $\mathrm{Mb} \geq 6.0$ earthquake occurrences in 25, 50 and 75 years, these values were estimated as $52 \%, 77 \%$ and $89 \%$, respectively. Also, the recurrence times of $\mathrm{Mb} \geq 5.0, \mathrm{Mb} \geq 5.5$ and $\mathrm{Mb} \geq$ 6.0 earthquakes were calculated as 9, 17 and 32 years, respectively. All detailed statistics can be found from Tables 3 and 4 in Bilim (2003). These results indicate that there is an earthquake hazard in the intermediate/ long term in Central Anatolia.

Çobanoğlu et al. (2006) achieved a risk analysis for the Eastern Mediterranean region, including some parts of the CAR, by using different statistical models such as Poisson, Gumbell and Exponential distribution models, and they realized their study by defining the interval of earthquake occurrences and recurrence times. The $b$-value of the G-R scaling law was estimated as 0.96 for the study region. According to the Poisson model in Çobanoğlu et al. (2006), the probability values of $\mathrm{Ms} \geq 5.0$ (surface wave magnitude) earthquake occurrences in 20,50 and 75 years were calculated as $94 \%, 99 \%$ and $99 \%$, respectively. For
$\mathrm{Ms} \geq 5.5$ earthquake occurrences in 20, 50 and 75 years, the probability values were estimated as $60 \%, 90 \%$ and $97 \%$, respectively. However, for $\mathrm{Ms} \geq 6.0$ earthquake occurrences in 20, 50 and 75 years, probability values were computed as $26 \%, 53 \%$ and $68 \%$, respectively. Also, the recurrence times of $\mathrm{Ms} \geq 5.0, \mathrm{Ms} \geq 5.5$ and $\mathrm{Ms} \geq 6.0$ earthquakes were calculated as 7,22 and 66 years, respectively (one can find all details for the results of the other models in Çobanoğlu et al. 2006). As shown in the results of Bilim (2003), an important seismic hazard can be considered in the intermediate/ long term in some parts of Central Anatolia.

A probabilistic earthquake hazard analysis for the western Anatolian region was carried out by using the G-R magnitude-frequency scaling law in Kahraman et al. (2008). The $b$-value of the G-R relationship was estimated as 0.84 with the maximum likelihood approach. According to the Poisson model in Kahraman et al. (2008), the probability values of M $\geq 5.0$ earthquake occurrences in 50,75 and 100 years were computed as $100 \%, 100 \%$ and $100 \%$, respectively. For $M \geq 5.5$ earthquake occurrences in 50, 75 and 100 years, the probability values were calculated as $100 \%, 100 \%$ and $100 \%$, respectively. Also, for $\mathrm{Ms} \geq 6.0$ earthquake occurrences in 50,75 and 100 years, probabilities were estimated as $100 \%, 100 \%$ and $100 \%$, respectively. Also, the return periods of $\mathrm{M} \geq 5.0, \mathrm{M} \geq 5.5$ and $\mathrm{M} \geq 6.0$ earthquakes were estimated as 1.3, 3.5 and 9.8 years, respectively (one can find all details of the results of the other models in Kahraman et al. 2008). Thus, earthquake hazard in western Anatolia was statistically defined as the probability of occurrence and recurrence intervals for earthquakes with certain magnitudes in the intermediate/long term.

Özmen (2015) made an assessment of seismic activity in the CAR of Turkey considering the data with $\mathrm{Mw} \geq 4.0$ (moment magnitude) earthquakes which occurred between 1900 and 2011, and Gumbel Extreme Values method was used to estimate the statistical earthquake hazard parameters. The seismic assessment for the CAR was provided by evaluating the past events in six sub-regions covered by the co-ordinates $38^{\circ} \mathrm{N}$ and $41.0^{\circ} \mathrm{N}$ in latitude and the co-ordinates $30^{\circ} \mathrm{E}$ and $35^{\circ} \mathrm{E}$ in longitude. The occurrence probabilities and recurrence times for each source region were estimated for strong/large earthquakes which might occur in the future. According to the results of this study, the NAFZ has the largest seismic hazard and therefore this zone may generate a significant source of earthquake-related hazard in the CAR. Thus, this study will contribute to earthquake scenario studies and provide related statistics in preparing the earthquake hazard maps in and around the CAR.

Based on the results of this study and literature information, it can be clearly said that the region- 
time-magnitude assessments of seismicity may be the evidence of the earthquake hazard potential in the Central Anatolian Region at the beginning of 2019. Therefore, statistical parameters such as $b$-value, $D c$ value, $Z$-value, annual probabilities and recurrence times and their relationship with each other are quite important in order to make a more sensitive estimation before the occurrence of strong/large earthquakes in the intermediate/long term. The last earthquakes in this study region are recorded on 10 January 2016 in Hacıdurakl1-Kırşehir and on 20 September 2020 in Bor-Niğde, and for this reason special interest must be given to the anomaly regions of seismotectonic parameters to make a reliable and an updated earthquake hazard analysis.

\section{CONCLUSIONS}

A comprehensive statistical region-time-magnitude analysis of earthquake occurrences in the Central Anatolian Region of Turkey was realized by considering the most frequently used seismicity parameters such as magnitude completeness Mcomp, $b$-value of frequency-magnitude distribution, $D c$-value of fractal dimension, standard normal deviate $Z$-value, recurrence time, and annual probability. For this purpose, a homogeneous catalogue consisting of 10,146 earthquakes with $1.0 \leq M_{d} \leq 5.7$ for shallow events (depth $<70 \mathrm{~km}$ ) between 30 July 1975 and 29 December 2018 was used and spatio-temporal changes of earthquake behaviours were mapped for the beginning of 2019. Reasenberg's algorithm was used to eliminate dependent events from the catalogue. Mcomp was calculated as 2.6. After declustering process and separating the earthquakes smaller than Mcomp, about $63.27 \%$ of total events were removed from the catalogue and only 3727 events were used to map the regional distributions of $b$-value, $Z$-value and recurrence times. The fundamental conclusions of this statistical study can be given as follows:

(i) The $b$-value was calculated as $1.26 \pm 0.07$ with the maximum likelihood process by taking Mcomp $=2.6$, and this intermediate $b$-value can be explained by the fact that the CAR has a great number of small/moderate earthquakes. This situation can also be interpreted as large heterogeneity and low stress relaxation.

(ii) Using $95 \%$ confidence limits by using linear regression and scale invariance between 5.03 and $81.09 \mathrm{~km}$, the $D c$-value was estimated as $1.31 \pm 0.03$, i.e. relatively small, and therefore earthquake activity is more clustered at smaller scales (or in larger areas). This small $D c$-value can be given as a dominant structural feature resulting from the clusters depending on the range of chosen distance. (iii) Temporal evaluations of annual probabilities and recurrence times for the selected magnitude levels suggest that the CAR has an intermediate/long-term earthquake hazard after 2021 for the possibility of strong/large earthquake occurrences $\left(M_{d} \geq 5.0\right)$.

(iv) Temporal changes of $b$ and $D c$-values show significant fluctuations, in the form of increasing $D c$-value and decreasing $b$-value, before the occurrence of a stronger earthquake. These variations can be thought to be related to stress changes in these time intervals and may be preliminary evidences for the assessment of the next earthquake occurrence in the intermediate/long term in the CAR.

(v) The areas with the smallest $b$-values $(<0.8)$ were generally calculated in all parts of the study region including the north-western end of the CAR, along the Tuzgölü Fault Zone, Salanda fault, Niğde fault and throughout the south-western parts of the Central Anatolian Fault Zone, whereas other smaller values $(0.8<b<1.0)$ were observed in the southwestern part of the CAR. These regions with small $b$-values may be related to a higher stress release or low heterogeneity degree and high strain due to the active tectonics of the CAR.

(vi) Several seismic quiescence regions centred at $39.48^{\circ} \mathrm{N}-32.63^{\circ} \mathrm{E}$ (the northwest ends of the Tuzgölü Fault Zone and study region), at $39.13^{\circ} \mathrm{N}-35.18^{\circ} \mathrm{E}$ (the northeast of the Salanda fault, and between the Salanda fault and the Central Anatolian Fault Zone), at $38.76^{\circ} \mathrm{N}-$ $36.01^{\circ} \mathrm{E}$ (the northeast parts of the Central Anatolian Fault Zone), at $38.14^{\circ} \mathrm{N}-32.72^{\circ} \mathrm{E}$ (the southwest of Tuzgölü), at $37.85^{\circ} \mathrm{N}-34$ $.59^{\circ} \mathrm{E}$ (the southeast end of the Tuzgölü Fault Zone, between the Tuzgölü Fault Zone and the Central Anatolian Fault Zone), and at $37.24^{\circ} \mathrm{N}-$ $35.34^{\circ} \mathrm{E}$ (between the Central Anatolian Fault Zone and Yakapınar Göksun Fault Zone) were observed at the beginning of 2019.

(vii) Regional variations of the recurrence times of different magnitude levels such as $M_{d}=5.0$, $M_{d}=5.5$ and $M_{d}=6.0$ show that recurrence times smaller than 10 years for strong/large earthquakes were observed in the northwest parts of the Tuzgölü Fault Zone, in the northeast end of the Central Anatolian Fault Zone, and between the Central Anatolian Fault Zone and Yakapınar-Göksun Fault Zone. Thus, region-time variations of recurrence times for strong earthquakes indicate an intermediate/ long-term earthquake hazard in comparison to occurrences in the short term in the CAR.

Thus, anomaly regions with a smaller $b$-value, a 
higher $Z$-value and intermediate recurrence times may be thought as the most likely regions for strong/large earthquake occurrences in the future. For this reason, the correlations between these seismicity parameters may provide preliminary and useful information on earthquake hazard for strong/large earthquake occurrences in the CAR of Turkey in the intermediate and long term. If these behaviours can be identified as reliable characteristics of earthquake activity, they can contribute to preliminary evaluation of seismic hazard potential in the Central Anatolian Region of Turkey.

\section{ACKNOWLEDGEMENTS}

The author would like to thank the editor and anonymous reviewers for their useful and constructive suggestions in improving this paper. I am grateful to KOERI and AFAD for providing earthquake catalogues.

\section{REFERENCES}

Aki, K. 1965. Maximum likelihood estimate of $b$ in the formula $\log N=a-b m$ and its confidence limits. Bulletin of Earthquake Research Institute of Tokyo University 43, 237-239.

Aktuğ, B., Parmaksız, E., Kurt, M., Lenk, O., Kılıçoğlu, A., Gürdal, M.A., Özdemir, S. 2013. Deformation of Central Anatolia: GPS implications. Journal of Geodynamics 67, 78-96.

Ali, S.M. 2016. Statistical analysis of seismicity in Egypt and its surroundings. Arabian Journal of Geosciences 9 (52), 2-16.

Arabasz, W.J., Hill, S.J. 1996. Applying Reasenberg's cluster analysis algorithm to regional earthquake catalogs outside California (abstract). Seismological Research Letters 67 (2), 30.

Bayrak, Y., Öztürk, S., Çınar, H., Kalafat, D., Tsapanos, T., Koravos, G-Ch., Leventakis, G.A. 2009. Estimating earthquake hazard parameters from instrumental data for different regions in and around Turkey. Engineering Geology 105, 200-210.

Bilim, F. 2003. Investigation of seismic hazard in Çankırı, Turkey, using Gumbel's first asymptotic distribution of extreme values. Journal of Balkan Geophysical Society 6 (3), 158-164.

Bowman, D.D., King, G.C.P. 2001a. Accelerating seismicity and stress accumulation before large earthquakes. Geophysical Research Letters 28, 4039-4042.

Bowman, D.D., King, G.C.P. 2001b. Stress transfer and seismicity changes before large earthquakes, C.R. Acad. Sci. Paris. Sciences de la Terre et des planets 333, 591-599.

Bozkurt, E. 2001. Neotectonics of Turkey-a synthesis. Geodinamycs Acta 14, 3-30.

Chen, C.C., Wang, W.C., Chang, Y.F., Wu, Y.M., Lee, Y.H. 2006. A correlation between the $b$-value and the fractal dimension from the aftershock sequence of the 1999 Chi-Chi, Taiwan, earthquake. Geophysical Journal International 167, 1215-1219.

Chiba, K. 2019. Spatial and temporal distributions of $b$-values related to long-term slow-slip and low-frequency earthquakes in the Bungo Channel and Hyuganada regions, Japan. Tectonophysics 757, 1-9.

Console, R., Montuori, C., Murru, M. 2000. Statistical assessment of seismicity patterns in Italy: Are they precursors of subsequent events? Journal of Seismology 4, 435-449.

Çobanoğlu, İ., Bozdağ, Ş., Dinçer, İ., Erol, H. 2006. Statistical approaches to estimating the recurrence of earthquakes in the Eastern Mediterranean region. Istanbul University English Faculty of Earth Sciences Journal 19 (1), 91-100 (in Turkish with English abstract).

Dirik, K., Göncüoğlu, M.C. 1996. Neotectonic characteristics of Central Anatolia. International Geology Reviews 38, 807-817.

Emre, Ö., Duman, T.Y., Özalp, S., Şaroğlu, F., Olgun, Ş., Elmac1, H., Çan, T. 2018. Active fault database of Turkey. Bulletin of Earthquake Engineering 16, 32293275.

Enescu, B., Ito, K. 2002. Spatial analysis of the frequencymagnitude distribution and decay rate of aftershock activity of the 2000 Western Tottori earthquake. Earth Planets Space 54, 847-859.

Erdik, M., Alpay, B.Y., Onur, T., Sesetyan, K., Birgoren, G. 1999. Assessment of earthquake hazard in Turkey and neighboring regions. Annals of Geophysics 42, 1125-1138.

Frohlich, C., Davis, S. 1993. Teleseismic b-values: Or, much ado about 1.0. Journal of Geophysical Research 98 (B1), 631-644.

Gentili, S., Peresan, A., Talebi, M., Zare, M., Giovambattista, R.D. 2019. A seismic quiescence before the 2017 Mw 7.3 Sarpol Zahab (Iran) earthquake: Detection and analysis by improved RTL method. Physics of the Earth and Planetary Interiors 290, 10-19.

Gnyp, A. 2007. Fractal variations of the Transcarpathians, West Ukraine, seismicity and their potential relation to changing phases of local cycles. Acta Geophysica 55 (3), 288-301.

Goltz, C. 1998. Fractal and chaotic properties of earthquakes. Lecture Notes in Earth Sciences 77, 178 pp. Springer-Verlag.

Gökten, E., Varol, B. 2010. General geology of the region and seismic sources. In: Başokur, A. (ed.) Geologicalgeophysical-geotechnical properties of soils west of the city of Ankara and dynamic behavior. Ankara University, 12-32 (In Turkish).

Grassberger, P., Procaccia, I. 1983. Measuring the strangeness of strange attractors. Physica D: Nonlinear Phenomena 9 (1-2), 189-208.

Gutenberg, R., Richter, C.F. 1944. Frequency of earthquakes in California. Bulletin of the Seismological Society of America 34, 185-188.

Habermann, R.E. 1983. Teleseismic detection in the Aleu- 
tian Island arc. Journal of Geophysical Research 88 (B6), 5056-5064.

Hirata, T. 1989. Correlation between the $b$-value and the fractal dimension of earthquakes. Journal of Geophysical Research 94, 7507-7514.

Joseph, J.D.R., Rao, K.B., Anoop, M.B. 2011. A study on clustered and de-clustered world-wide earthquake data using G-R recurrence law. International Journal of Earth Sciences and Engineering 4, 178-182.

Kagan, Y.Y. 2007. Earthquake spatial distribution: the correlation dimension. Geophys. J. Int. 168, 1175-1194.

Kahraman, S., Baran. T., Saatçı, İ.A., Şalk, M. 2008. The effect of regional borders when using the GutenbergRichter model, case study: Western Anatolia. Pure Applied Geophysics 165, 331-347.

Katsumata, K. 2011. Precursory seismic quiescence before the $\mathrm{Mw}=8.3$ Tokachi-oki, Japan, earthquake on 26 September 2003 revealed by a re-examined earthquake catalog. Journal of Geophysical Research 116, B10307.

Katsumata, K., Kasahara, M. 1999. Precursory seismic quiescence before the 1994 Kurile Earthquake (Mw = 8.3) revealed by three independent seismic catalogs. Pure Applied Geophysics 155, 43-470.

Koçyiğit, A. 2000. General neotectonic characteristics and seismicity of Central Anatolia: Haymana-TuzgölüUlukışla basins applied study (Workshop). Turkish Association of Petroleum Geologists Special Publication 5, 1-26. (In Turkish).

Matcharasvili, T., Chelidze, T., Javakhishvili, Z. 2000. Nonlinear analysis of magnitude and intervent time interval sequences for earthquakes of Caucasian region. Nonlinear Processes in Geophysics 7, 9-19.

Mogi, K. 1962. Magnitude-frequency relation for elastic shocks accompanying fractures of various materials and some related problems in earthquakes. Bulletin of Earthquake Research Institute of Tokyo University 40, 831-853.

Öncel, A.O., Wilson, T.H. 2002. Space-time correlations of seismotectonic parameters and examples from Japan and Turkey preceding the İzmit earthquake. Bulletin of the Seismological Society of America 92, 339-350.

Öncel, A.O., Wilson, T.H. 2004. Correlation of seismotectonic variables and GPS strain- measurements in western Turkey. Journal of Geophysical Research 109 (B11), B11306.

Özmen, B. 2015. Assessment of the statistical earthquake hazard parameters for the Central Anatolia region, Turkey. Arabian Journal of Geosciences 8, 6341-6351.

Özsayın, E., Dirik, K. 2007. Quaternary activity of the Cihanbeyli and Yeniceoba fault zones: İnönü-Eskişehir fault system, Central Anatolia. Turkish Journal of Earth Sciences 16, 471-492.

Öztürk, S. 2009. An application of the earthquake hazard and aftershock probability evaluation methods to Turkey earthquakes. PhD Thesis, Karadeniz Technical University, Trabzon, Turkey. (In Turkish with English abstract).
Öztürk, S. 2011. Characteristics of Seismic Activity in the Western, Central and Eastern Parts of the North Anatolian Fault Zone, Turkey: Temporal and Spatial Analysis. Acta Geophysica 59 (2), 209-238.

Öztürk, S. 2012. Statistical correlation between b-value and fractal dimension regarding Turkish epicentre distribution. Earth Sciences Research Journal 16 (2), 103-108.

Öztürk, S. 2013. A statistical assessment of current seismic quiescence along the North Anatolian Fault Zone: Earthquake precursors. Austrian Journal of Earth Sciences 106 (2), 4-17.

Öztürk, S. 2015. A study on the correlations between seismotectonic $b$-value and $D c$-value, and seismic quiescence $Z$-value in the Western Anatolian region of Turkey. Austrian Journal of Earth Sciences 108 (2), 172-184.

Öztürk, S. 2017. Space-time assessing of the earthquake potential in recent years in the eastern Anatolia region of Turkey. Earth Sciences Research Journal 21 (2), 67-75.

Öztürk, S. 2018. Earthquake hazard potential in the Eastern Anatolian region of Turkey: seismotectonic $b$ and $D c$ values and precursory quiescence $Z$-value. Frontiers of Earth Science 12 (1), 215-236.

Öztürk, S., Şahin, Ş. 2019. A statistical space-time-magnitude analysis on the aftershock occurrence of the July 21th, $2017 \mathrm{Mw}=6.5$ Bodrum-Kos, Turkey, earthquake. Journal of Asian Earth Sciences 172, 443-457.

Öztürk, S., Bayrak, Y., Çınar, H., Koravos, G.-Ch., Tsapanos, T.M. 2008. A quantitative appraisal of earthquake hazard parameters computed from Gumbel I method for different regions in and around Turkey. Natural Hazards 47, 471-495.

Pailoplee, S., Choowong, M. 2014. Earthquake frequencymagnitude distribution and fractal dimension in mainland Southeast Asia. Earth Planets Space 66, 8 pp.

Polat, O., Gok, E., Yılmaz, D. 2008. Earthquake hazard of the Aegean Extension region (West Turkey). Turkish Journal of Earth Sciences 17, 593-614.

Puangjaktha, P., Pailoplee, S. 2018. Temporal and spatial distributions of precursory seismicity rate changes in the Thailand-Laos-Myanmar border region: implication for upcoming hazardous earthquakes. Journal of Seismology 22, 303-313.

Radziminovich, N.A., Miroshnichenko, A.I., Zuev, F.L. 2019. Magnitude of completeness, $b$-value, and spatial correlation dimension of earthquakes in the South Baikal Basin, Baikal Rift System. Tectonophysics 759, 44-57.

Reasenberg, P.A. 1985. Second-order moment of Central California seismicity, 1969-1982. Journal of Geophysical Research 90 (B7), 5479-5495.

Reilinger, R.E., McClusky, S.C., Souter, B.J., Hamburger, M.W., Prilepin, M.T., Mishin, A., Balassanian, S. 1997. Preliminary estimates of plate convergence in the Caucasus collision zone from global positioning system measurements. Geophysical Research Letters 24, 1815-1818. 
Rodriguez-Perez, Q., Zuniga, F.R. 2018. Imaging b-value depth variations within the Cocos and Rivera plates at the Mexican subduction zone. Tectonophysics 734735, 33-43.

Roy, S., Ghosh, U., Hazra, S., Kayal, J.R. 2011. Fractal dimension and $b$-value mapping in the Andaman-Sumatra subduction zone. Natural Hazards 57, 27-37.

Şaroğlu, F., Emre, O., Kuşcu, O. 1992. Active fault map of Turkey. General Directorate of Mineral Research and Exploration, Ankara, Turkey Scholz, C.H. 1968. The frequency-magnitude relation of microfracturing in rock and its relation to earthquakes. Bulletin of the Seismological Society of America 58, 399-415.

Schorlemmer, D., Wiemer, S., Wyss, M. 2005. Variations in earthquake-size distribution across different stress regimes. Nature 437, 539-42.

Singh, C. 2016. Spatial variation of seismic $b$-values across the NW Himalaya. Geomatics, Natural Hazards and Risk 7 (2), 522-530.

Talebi, M., Zare, M., Madahi-Zadeh, R., Bali-Lashak, A. 2015. Spatial-temporal analysis of seismicity before the 2012 Varzeghan, Iran, Mw 6.5 earthquake. Turkish Journal of Earth Sciences 24, 289-301.

Telesca, L., Chen, Ch-ch. 2019. Fractal and spectral investigation of the shallow seismicity in Taiwan. Journal of Asian Earth Sciences 174, 1-10.

Ulusay, R., Tuncay, E., Sönmez, H., Gökçeoğlu, C. 2004. An attenuation relationship based on Turkish strong motion data and iso-acceleration map of Turkey. Engineering Geology 74 (3-4), 265-291.

Utsu, T. 1971. Aftershock and earthquake statistic (III): Analyses of the distribution of earthquakes in magnitude, time and space with special consideration to clustering characteristics of earthquake occurrence (1). Journal of Faculty of Science, Hokkaido University, Series VII (Geophysics) 3, 379-441.

Wiemer, S. 2001. A software package to analyze seismic- ity: ZMAP. Seismological Research Letters 72 (2), 373-382.

Wiemer, S., Wyss, M. 1994. Seismic quiescence before the Landers (M=7.5) and Big Bear (6.5) 1992 earthquakes. Bulletin of the Seismological Society of America 84 (3), 900-916.

Wiemer, S., Wyss, M. 2000. Minimum magnitude of completeness in earthquake catalogs: Examples from Alas$\mathrm{ka}$, the Western United States, and Japan. Bulletin of the Seismological Society of America 90 (3), 859-869.

Woessner, J., Wiemer, S. 2005. Assessing the quality of earthquake catalogues: Estimating the magnitude of completeness and its uncertainty. Bulletin of the Seismological Society of America 95 (2), 684-698.

Wu, Y.M., Chiao, Y.L. 2006. Seismic quiescence before the 1999 Chi-Chi, Taiwan, $M_{\mathrm{w}}$ 7.6 Earthquake. Bulletin of the Seismological Society of America 96 (1), 321-327.

Wyss, M., Burford, R.O. 1987. Occurrences of predicted earthquake on the San Andreas fault. Nature 329, 323 325.

Wyss, M., Martirosyan, A.H. 1998. Seismic quiescence before the M7, 1988, Spitak earthquake, Armenia. Geophysical Journal International 134 (2), 329-340.

Wyss, M., Sobolev, G.A., Clippard, J.D. 2004. Seismic quiescence precursors to two M7 earthquakes on Sakhalin Island, measured by two methods. Earth Planets Space 56, 725-740.

Yüksel, F.A. 1985. The earthquake activity and earthquake risk analyses of southwestern of Turkey. Istanbul University Engineering Faculty Journal of Earth Sciences 5 (1-2), 169-184. (In Turkish).

Zuniga, F.R., Lacan, P., Rodriguez-Perez, Q., MarquezRamirez, V.H. 2020. Temporal and spatial evolution of instrumented seismicity in the Trans-Mexican Volcanic Belt. Journal of South American Earth Sciences 98, 102390. 